\title{
Modulation of steroidogenic enzymes by orphan nuclear transcriptional regulation may control diverse production of cortisol and androgens in the human adrenal
}

\author{
Sinead N Kelly, T Joseph McKenna ${ }^{1}$ and Leonie S Young \\ Department of Surgery, Conway Institute of Biomolecular and Biomedical Research, University College Dublin, Ireland \\ ${ }^{1}$ Department of Investigative Endocrinology, St Vincent's University Hospital, Elm Park, Dublin, Ireland \\ (Requests for offprints should be addressed to L Young; Email: leonie.young@ucd.ie)
}

\begin{abstract}
The capacity of the adrenal to produce cortisol is controlled in part by 21-hydroxylase (CYP21) and the production of androgens by 17-hydroxylase/17-20-lyase (CYP17), in response to secretagogues including ACTH, angiotensin-II (A-II) and insulin. In this study we examined the capacity of human adrenocortical cells to produce cortisol and androgens in response to these secretagogues and their ability to regulate the expression of CYP21 and CYP17. In H-295 cells, forskolin and A-II were found to stimulate production of cortisol relative to androstenedione and a similar pattern of steroid production was noted in primary human adrenocortical cells. Both mRNA and protein expression of CYP21 was upregulated with forskolin and A-II alone and in combination, as detected by Northern and Western blotting. Whereas expression of CYP17 mRNA and protein was up-
\end{abstract}

regulated in the presence of forskolin and forskolin in combination with insulin. The ability of steroidogenic factor-1 (SF-1) and nur77 to regulate transcription of these enzymes was examined. Forskolin, A-II and insulin increased the protein expression of SF-1. Increased binding of SF-1 to its response element in the presence of forskolin, A-II and insulin was observed. Nur77 was expressed primarily in the zona glomerulosa and fasciculata. Increased protein expression of nur77 and the greatest binding of nur77 to its response element was seen when cells were stimulated with A-II in combination with forskolin. These data indicate that nur77 may preferentially regulate steroid enzyme genes relevant to cortisol production and thereby regulate differential cortisol and adrenal androgen production.

Journal of Endocrinology (2004) 181, 355-365

\section{Introduction}

Differential production of adrenal steroids is relative rather than absolute. Cells of the adrenal cortex are capable of producing a range of steroids, but the relative production of cortisol, androgens and aldosterone differs (Young et al. 2003). Steroid production is controlled in response to secretagogues both at the level of the substrate through the conversion of cholesterol to pregnenolone and at the level of gene transcription of the steroidogenic enzymes (Peter \& Dubuis 2000). Specific production of adrenal steroids results from the selective modulation of the steroid hydroxylases that catalyse the terminal steps of steroid biosynthesis (Parker \& Schimmer 1994). This is illustrated physiologically at the adrenarche and clinically in polycystic ovarian syndrome, where characteristic hyperandrogenaemia is associated with an induction of CYP17 (Barnes \& Rosenfield 1989, McKenna \& Cunningham 1995, Gell et al. 1998).

Classic secretagogues including adrenocorticotrophin $(\mathrm{ACTH})$, angiotensin II (A-II) and more recently novel factors such as insulin, upregulate steroid production through the regulation of key steroidogenic enzymes (Bird et al. 1993b, Qin \& Rosenfield 1998). 21-hydroxyalse (CYP21) regulates cortisol and aldosterone production by conversion of 17-hydroxyprogesterone to 11-deoxycortisol and progesterone to 11-deoxycorticosterone in the aldosterone pathway, whereas 17-hydroxylase/17-20-lyase (CYP17) is primarily concerned with androgen production through the conversion of pregnenolone to $17 \alpha-$ hydroxypregnenolone and on to dehydroepiandrosterone and progesterone to $17 \alpha$-hydroxyprogesterone.

Orphan members of the nuclear receptor superfamily play an important role in mediating transcriptional regulation of several steroid hydroxylase genes. Common binding motifs described within steroidogenic regulatory elements suggest that a shared promoter interacts with a mutual transcription factor to regulate the expression of the hydroxylase enzymes in a co-ordinated manner (Rice et al. 1991). Sequences matching the steroidogenic factor-1 (SF-1) binding site have been found upstream of all hydroxylase genes, suggesting that SF-1 is a 
global regulator of steroidogenic cytochrome P450 gene expression (Lala et al. 1992, Morohashi et al. 1992).

Nur77 (also known as NGFIB/N10/NAK1/TR3) is a member of the immediate early response gene family and closely resembles SF-1 (Zhang \& Mellon 1997). Recently nur77 response elements have been identified on the promoter region of CYP21 and the transcription factor has been shown to be involved in the regulation of CYP21mediated cortisol production in Y1 mouse adrenal cortical cells (Wilson et al. 1993, Chang \& Chung 1995).

We hypothesise that differential production of cortisol and adrenal androgens is through the alternate transcriptional regulation of key steroidogenic enzymes. In this study we provide evidence that while ACTH, A-II and insulin all signal through SF-1 to regulate the expression of CYP21 and CYP17, ACTH and A-II can also signal through nur77 to regulate the gene transcription of CYP21 and thereby modulate cortisol production. Differential regulation of CYP21 and CYP17 may explain in part the divergence of cortisol and adrenal androgen production seen under physiological and pathophysiological conditions.

\section{Materials and Methods}

Preparation and stimulation of cell suspensions and H-295 cells

Twenty-three human adrenal glands, surgically removed at the time of resection for renal transplantation, were used in this study. Five adrenal glands were used for each experimental treatment. Adrenal glands were prepared as described previously (Clarke et al. 1996, Fearon et al. 1998). Excess fat and connective tissue were removed and the adrenal glands were diced. The tissue was incubated at $37^{\circ} \mathrm{C}$ for $20 \mathrm{~min}$ in Eagle's Modified Essential Medium (EMEM) containing collagenase, type II $(2 \mathrm{mg} / \mathrm{ml})$. The tissue suspension was centrifuged at $400 \mathrm{~g}$ for $10 \mathrm{~min}$ and the supernatant discarded. The pellet was resuspended in $0 \cdot 2 \%(\mathrm{w} / \mathrm{v}) \mathrm{BSA}$ in EMEM and the cells passed through a nylon mesh $(100 \mu \mathrm{m})$. The cell suspension was washed and centrifuged as before and resuspended in EMEM containing $0.5 \% \mathrm{BSA}(\mathrm{w} / \mathrm{v}), 8 \mathrm{mM}$ calcium and $1 \mathrm{mM}$ ascorbic acid to a concentration of $10^{6} \mathrm{cell} / \mathrm{s} / \mathrm{ml}$ in the presence and absence of $10^{-7} \mathrm{M} \alpha 1-24 \mathrm{ACTH}, 10^{-7} \mathrm{M}$ A-II or $10^{-7} \mathrm{M}$ insulin. Cells were incubated for $2 \mathrm{~h}$ at $37^{\circ} \mathrm{C}$.

$\mathrm{H}-295$ cells were obtained from the American Type Culture Collection (Rockville, MD, USA). Cells were maintained in supplemented RPMI $(5 \mu \mathrm{g} / \mathrm{ml}$ insulin, $10 \mu \mathrm{g} / \mathrm{ml}$ transferin, $30 \mathrm{nM}$ sodium selinite, $10 \mathrm{nM}$ hydrocortisone, $10 \mathrm{nM} \quad \beta$-estradiol, $10 \mathrm{mM}$ HEPES, $2 \mathrm{mM}$ glutamine and $2 \%$ foetal calf serum $(\mathrm{w} / \mathrm{v}))$ grown in $75-\mathrm{cm}^{2}$ flasks at $37^{\circ} \mathrm{C}$ under an atmosphere of $5 \% \mathrm{CO}_{2}$. Cells were serum- and steroid-depleted $24 \mathrm{~h}$ prior to treatment. Cells were incubated for either 2 or $24 \mathrm{~h}$ in the presence or absence of $10^{-7} \mathrm{M}$ forskolin, $10^{-7} \mathrm{M}$
A-II, $10^{-7} \mathrm{M}$ insulin, forskolin in combination with A-II or forskolin in combination with insulin. The supernatants and cells were removed and stored for steroid measurement and protein extraction respectively.

\section{Steroid measurement}

Cortisol and androstenedione were measured in human cell suspensions and supernatants from H-295 stimulated cells. Cortisol levels were measured using an 'in house' RIA, as previously described (Clarke et al. 1996). Cell lysates and supernatants were incubated with a specific anti-cortisol antibody (Guildhay, Guildford, Surrey, UK) and iodinated cortisol (Amersham) at $4{ }^{\circ} \mathrm{C}$ overnight. Bound and free fractions were separated with 1\% dextrangelatin coated charcoal in borate. Androstenedione was measured using commercially available RIA kits (Diagnostic Systems Laboratories, Webster, TX, USA). Androstenedione cross reactivity with cortisol $<0 \cdot 04 \%$.

\section{Fixed $\mathrm{H}-295$ cells}

$\mathrm{H}-295$ cells were seeded at $5 \times 10^{5}$ cells per well in six well culture plates (Costar, Acton, MA, USA) on adherent coverslips (Nunc, Napeville, IL, USA) in the presence and absence of $10^{-7} \mathrm{M}$ forskolin for $2 \mathrm{~h}$ at $37^{\circ} \mathrm{C}$ in $5 \% \mathrm{CO}_{2}$. At the end of the incubation period cells were fixed on coverslips in absolute alcohol for $10 \mathrm{~min}$.

\section{Immunohistochemistry and cytochemistry}

An immunohistochemical technique was employed for the identification and localisation of CYP21, CYP17 and nur77 in human adrenal gland cryo-sections and H-295 cell cultures. Adrenal cryo-sections, $7 \mu \mathrm{m}$, were immunoblocked in serum for $90 \mathrm{~min}$ and incubated with a primary rabbit anti-porcine CYP17, 1:40; rabbit anti-ovine CYP21, 1:40 (Prof. J I Mason, Department of Clinical Biochemistry, Edinburgh, UK); goat anti-human nur77, $5 \mu \mathrm{g} / \mathrm{ml}$ (sc-7014, Santa Cruz Biotechnology Inc., CA, USA) for $1 \mathrm{~h}$ at room temperature and subsequently with either anti-rabbit or anti-goat horseradish peroxidase secondary antibody, 1:200, for $1 \mathrm{~h}$ at room temperature. Sections were developed in 3,3'-diaminobenzidine tetrahydrochloride for $7 \mathrm{~min}$ and counter stained with Mayer's haematoxylin. Negative controls were performed either using blocking peptides to nur77 (sc-7014P, Santa Cruz Biotechnology Inc) or by omitting the primary antibody and no peroxidase staining was observed.

Fixed H-295 cells were immuno-blocked in serum for $90 \mathrm{~min}$ and incubated with a primary goat anti-human nur77, $5 \mu \mathrm{g} / \mathrm{ml}$ (sc-7014, Santa Cruz Biotechnology Inc) for $1 \mathrm{~h}$ at room temperature and subsequently anti-goat horseradish peroxidase secondary antibody, 1:200, for $1 \mathrm{~h}$ at room temperature and developed as described above. 


\section{Immunofluorescence}

H-295 cells were prepared as above and incubated in goat serum for 60 mins. Rabbit anti-human SF-1 $(50 \mu \mathrm{g} / \mathrm{ml}$ in 10\% human serum, PA1-800, Affinity Bioreagents, Golden, CO, USA) was placed on each slide for 90 mins. The sections were rinsed in PBS and incubated with the corresponding secondary fluorochrome conjugated antibody (1:100, TRITC labelled) for $60 \mathrm{~min}$. Sections were rinsed in PBS and mounted (Dako, Glostrup, Denmark). Sections were examined under fluorescent light.

\section{Northern analysis}

Total RNA was isolated from stimulated H-295 cells using RNeasy extraction kit (Qiagen) at specific times after treatment. RNA was quantified by u.v. absorption. $10 \mu \mathrm{g}$ of RNA was electrophoresed on a formaldehyde agarose gel and transferred to a nylon membrane (Bio-Rad) by pressure blotting overnight and was incubated for $3 \mathrm{~h}$ at $80{ }^{\circ} \mathrm{C}$.

Prehybridisation was carried out at $42{ }^{\circ} \mathrm{C}$ for $3 \mathrm{~h}$ in a final buffer composition of $45 \%$ formamide, $4 \times \mathrm{SSC}$, $0 \cdot 1 \mathrm{M}$ Na phosphate, $0 \cdot 1 \% \mathrm{Na}$ pyrophosphate, $0 \cdot 1 \%$ SDS and $250 \mu \mathrm{g} / \mathrm{ml}$ Herring sperm. Hybridisations were performed in the same buffer at $42{ }^{\circ} \mathrm{C}$ overnight with antisense probes to CYP21 (Accession no. M12792, 16-324 b.p.) or CYP17 (Accession no. M14564, 48-349 b.p.) mRNA (Prof. W E Rainey, Department of Obstetrics and Gynecology, Dallas, TX, USA) using $\alpha-{ }^{32} \mathrm{P}-\mathrm{dCTP}$ and a random primer-labelling system (Promega). The blots were then washed in $2 \times \mathrm{SSC}$ containing $0.5 \% \mathrm{SDS}$ at room temperature for 10 mins and again at $42{ }^{\circ} \mathrm{C}, 55^{\circ} \mathrm{C}$ for 10 mins before they were exposed to film at $-80^{\circ} \mathrm{C}$ using intensifying screens. Results were assessed directly by Eagle Eye (Stratagene, La Jolla, CA, USA) image analysis and compared with levels of 28S RNA in the same lane.

\section{Protein extraction and quantification}

Protein was extracted from H-295 cells by incubation in lysis buffer (PBS, 1\% Igepal and 0.5\% deoxycholic acid) supplemented with PMSF $10 \mu \mathrm{g} / \mathrm{ml}$ and aprotinin $1.5 \mu \mathrm{g} /$ $\mathrm{ml}$ for 30 mins. Protein was quantified using BCA assay kit (Pierce Chemicals Co., IL, USA). Nuclear protein extractions of H-295 were performed using NE-Per nuclear and cytoplasmic extraction kits (Pierce Chemicals, Rockford, IL, USA) according to manufacturer's instructions.

\section{Western analysis}

Western analysis was performed by SDS-PAGE on a discontinuous acrylamide gel. $30 \mu \mathrm{g}$ of protein were electrophoresed through $4 \%$ stacking $12 \cdot 5 \%$ resolving gel at $120 \mathrm{~V}$ for $2 \mathrm{~h}$. Gels were transferred to nitrocellulose membrane at $250 \mathrm{~mA}$ for $1 \mathrm{~h}$. Membranes were blocked for $1 \mathrm{~h}$ at $37^{\circ} \mathrm{C}$ in $5 \%$ non-fat dry milk and incubated overnight in either a primary rabbit anti-porcine CYP17, 1:500; rabbit anti-ovine CYP21, 1:1000; rabbit antihuman SF-1 (PA1-800, Affinity Bioreagents), 1:1000 and goat anti-human nur77 (sc-7014, Santa Cruz Biotechnology Inc), 1:500 and subsequently with either anti-rabbit, 1:1000 or anti-goat 1:1000 horseradish peroxidase secondary antibody (Santa Cruz Biotechnology Inc). Membranes were developed for 1 minute in luminol (Santa Cruz Biotechnology Inc), and autoradiographs were developed using standard photographic techniques.

\section{Electrophoretic mobility shift assays (EMSA)}

Nuclear protein extracts were prepared as described above. For EMSA, $5 \mu \mathrm{g}$ of nuclear extract was incubated for $20 \mathrm{~min}$ in the presence of $20 \mathrm{mM}$ HEPES, pH 7.9, $5 \mathrm{mM}$ $\mathrm{MgCl}_{2}, 20 \%$ glycerol, $100 \mathrm{mM} \mathrm{KCl,} \mathrm{0.2} \mathrm{mM} \mathrm{EDTA,} \mathrm{8 \%}$ Ficoll, $600 \mathrm{mM} \mathrm{KCl}, 500 \mathrm{ng} / \mu \mathrm{l}$ poly dIdC (deoxyinosinicdeoxycytidylic) acid, $50 \mathrm{mM}$ DTT and $\alpha_{-}{ }^{32} \mathrm{P}-\mathrm{dCTP}-$ labelled double-stranded oligonucleotide. For supershift experiments, antibodies to SF-1 (PA1-800, Affinity Bioreagents) or nur77 (sc-7014X, Santa Cruz Biotechnology Inc) were added following the initial $20 \mathrm{~min}$ incubation, then incubated for a further $20 \mathrm{~min}$. The samples were electrophoresed through a $5 \cdot 5 \%$ nondenaturing polyacrylamide gel in $0.5 \times$ Tris Borate-EDTA buffer. For competition studies, the reaction was performed as described with $50 \times$ molar excess of unlabelled probe. The following oligonucleotides were designed to incorporate the native human CYP21 (for nur77 binding) and CYP17 (for SF-1 binding) promoter sequences: SF-1 (CYP17, NM_000102) 5'-TTGCAAGCCTTGACTCCTGAG CCCAGATACCA-3', nur77 (CYP21, NM_000500) 5'CTGGATGCAGGAAAAAGGTCAGGGTTGCACTT$3^{\prime}$. The consensus sequence for the SF-1 and nur77 binding elements is underlined (Wilson et al. 1991, Hanley et al. 2001).

\section{Chemicals}

All chemicals were obtained from Sigma unless otherwise specified.

\section{Statistics}

Statistics were performed using the Wilcoxon Signed Rank test for non-parametric data, with significance accepted at the 5\% level.

\section{Results}

Functional analysis of human adrenocortical cells and H-295 cell line

The ability of primary human adrenal cortical cells and the ability of adrenocortical tumour cell line, H-295, to 
A
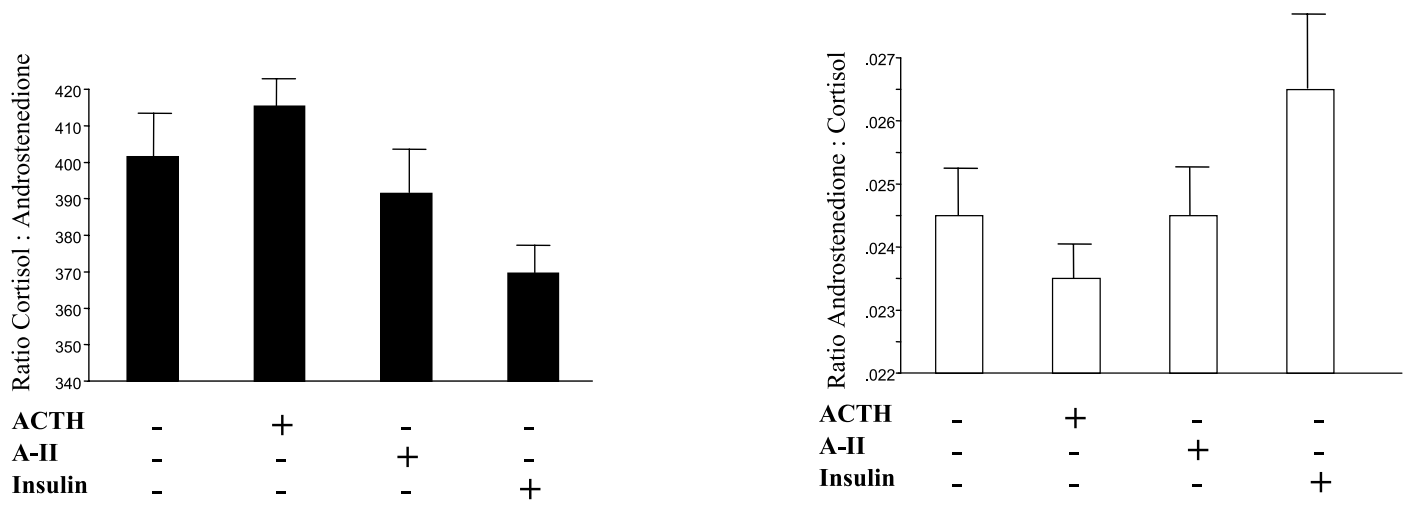

B

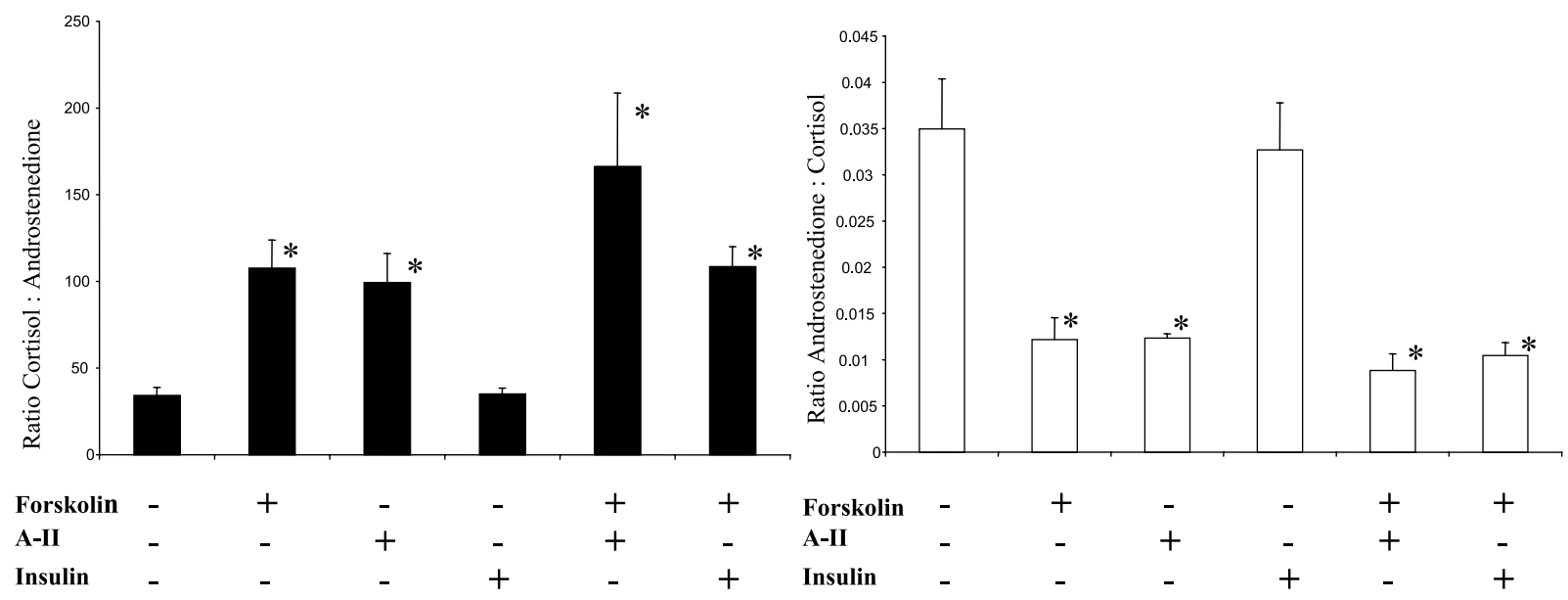

Figure 1 (A) Ratio of cortisol to androstenedione production and androstenedione to cortisol production in human adrenocortical cells in the presence $(+)$ and absence $(-)$ of $10^{-7} \mathrm{M} \mathrm{ACTH}, 10^{-7} \mathrm{M} \mathrm{A}-\mathrm{II}$ and $10^{-7} \mathrm{M}$ insulin. Mean \pm S.E.M., $n=5$ adrenals for each treatment group. (B) Ratio of cortisol to androstenedione production and androstenedione to cortisol production in $\mathrm{H}-295$ cell line in the presence $(+)$ and absence $(-)$ of $10^{-7} \mathrm{M}$ forskolin, $10^{-7} \mathrm{M} \mathrm{A-II}$ and $10^{-7} \mathrm{M}$ insulin. Mean \pm S.E.M., $n=10$ individual experiments; ${ }^{*}$ significantly different from control cells without addition of secretagogues, $P<0 \cdot 05$.

differentially produce cortisol and androstenedione in response to the secretagogues ACTH, A-II and insulin were examined. Human adrenocortical cells were found to produce both cortisol and androstenedione. The production of these steroids differed following stimulation with ACTH compared with insulin. ACTH produced more cortisol relative to androstenedione compared with control unstimulated cells, whereas insulin produced more androstenedione relative to cortisol when compared with control, though these differences did not reach statistical significance (Fig. 1A). There was no alteration in steroid production in primary adrenocortical cells treated with A-II compared with control. H-295 cells were used as a model to examine the response of adrenocortical cells to these secretagogues. Forskolin, the adenylate cyclase activating agent, was used as a functional analogue of ACTH as the H-295 cell line does not express a functional ACTH receptor. A-II was used to activate the protein kinase C (PKC) pathway. Forskolin and A-II were found to produce more cortisol relative to androstenedione compared with control cells (Fig. 1B) $\quad(P<0 \cdot 05)$. Forskolin in combination with A-II also significantly increased the production of cortisol relative to androstenedione $(P<0 \cdot 05)$. There was, however, no alteration in steroid production in cells treated with both insulin and forskolin compared with cells treated with forskolin alone. 
A
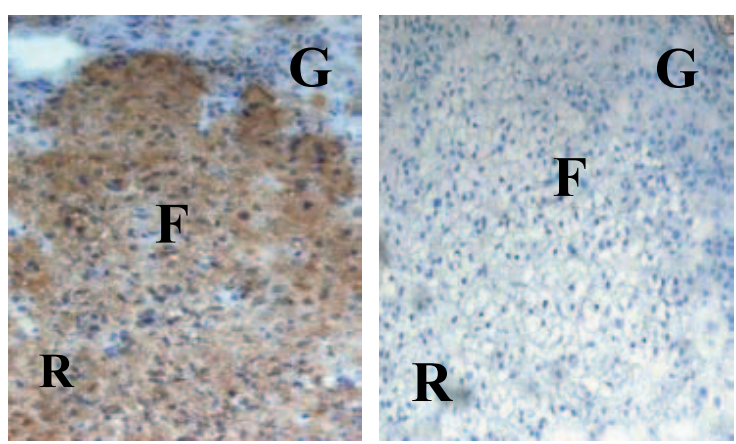

B
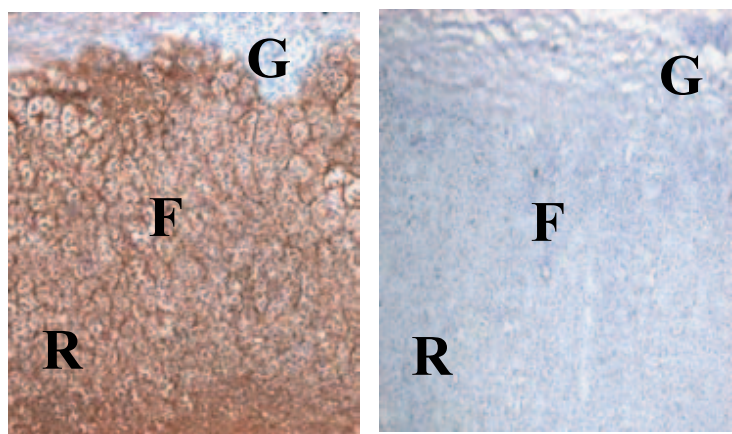

Figure 2 Photomicrographs showing immunohistochemical stain for (A) CYP21, (B) CYP17 in human adrenocortical cryosections counterstained with haematoxylin (left) and matched negative controls (right). Positive cells are indicated by a brown stain. G, glomerulosa; F, fasciculata; $\mathrm{R}$, reticularis. Original magnification $\times 200$.

Conversely, insulin alone did not alter steroid production in $\mathrm{H}-295$ cells.

\section{Immunolocalisation of hydroxysteroid enzymes}

Differential production of adrenal steroids is through the specific regulation of key steroidogenic enzymes. The traditional functional and histological characterisation of the human adrenal cortex was correlated with the expression of key steroidogenic enzymes concerned with the production of cortisol and androgens. CYP21 was localised in the zona fasciculata, zona reticularis and to a lesser extent the zona glomerulosa (Fig. 2A). CYP17 was localised to the zona fasciculata and zona reticularis, and was found to be absent from the zona glomerulosa (Fig. $2 \mathrm{~B})$. Both of these steroid enzymes were expressed within the cytosol of adrenocortical cells.

\section{$m R N A$ expression of hydroxysteroid enzymes}

The ability of forskolin, A-II and insulin to regulate CYP21 mRNA following $16 \mathrm{~h}$ incubation was examined.
A

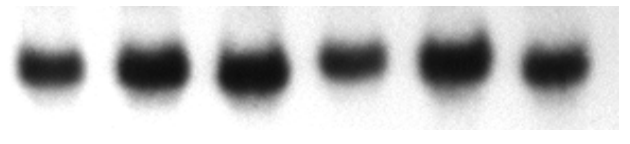

CYP21
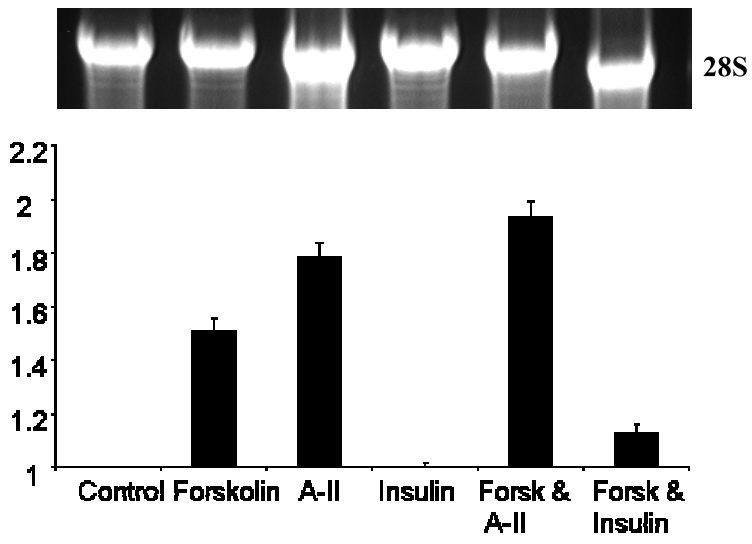

B

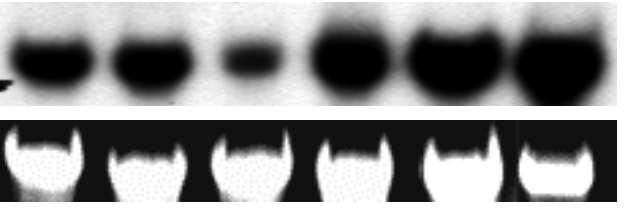

CYP17

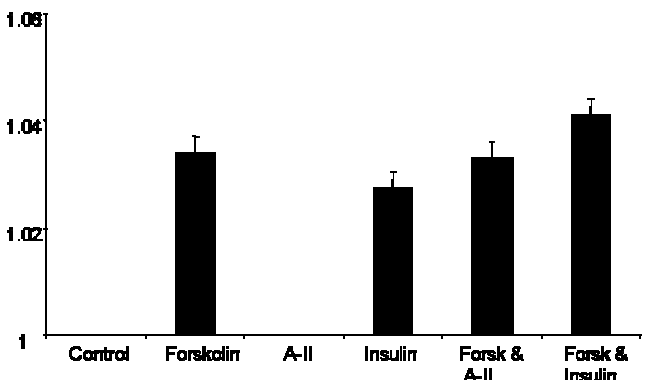

Figure 3 Representative Northern blot of (A) CYP21 and (B) CYP17 mRNA expression following stimulation in the $\mathrm{H}-295$ cells following stimulation with $10^{-7} \mathrm{M}$ forskolin, $10^{-7} \mathrm{M}$ A-II and $10^{-7} \mathrm{M}$ insulin. The presence and integrity of the 28S major RNA component for each lane was examined and found to be similar. Optical density readings were obtained. Control values were normalised to one and experimental groups were expressed as a ratio. Values are expressed as mean \pm S.E.M. $(n=3)$.

The action of forskolin and A-II alone and in combination resulted in an increase in CYP21 mRNA expression. No increase in expression was observed in the presence of insulin, whereas insulin in combination with forskolin was seen to inhibit the stimulatory effect of forskolin (Fig. 3A). The expression of CYP17 mRNA following $20 \mathrm{~h}$ incubation was examined. CYP17 mRNA was increased in 
A

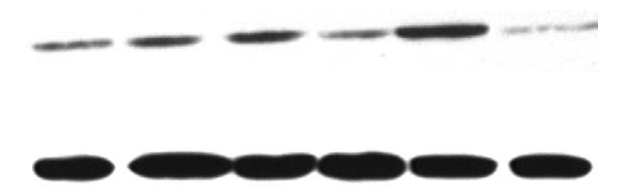

CYP21 $55 \mathrm{KDa}$

B-Actin 42KDa

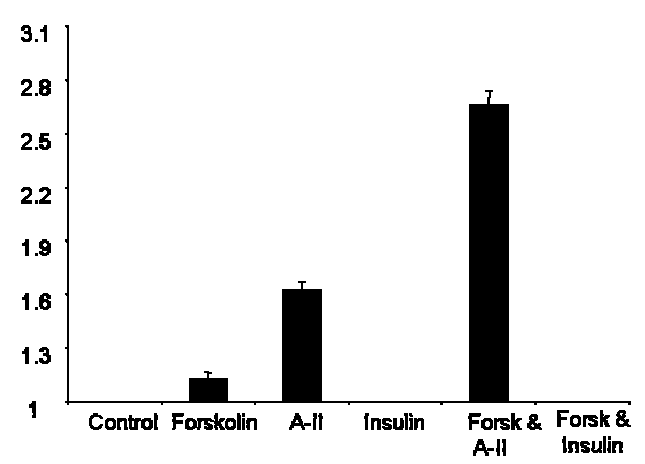

B
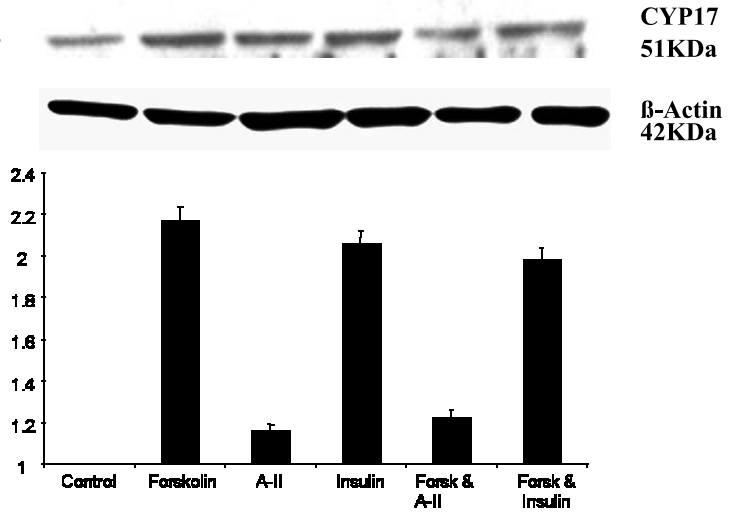

Figure 4 Representative protein immunoblot of (A) CYP21, (B) CYP17 total protein expression in $\mathrm{H}-295$ cells following $24 \mathrm{~h}$ stimulation with $10^{-7} \mathrm{M}$ forskolin, $10^{-7} \mathrm{M} \mathrm{A}$-II and $10^{-7} \mathrm{M}$ insulin. $\beta$-actin represents equal loading of samples. Optical density readings were obtained. Control values were normalised to one and experimental groups were expressed as a ratio. Values are expressed as mean \pm S.E.M. $(n=3)$.

response to forskolin and insulin. There was no alteration observed in the presence of A-II (Fig. 3B).

\section{Protein expression of hydroxysteroid enzymes}

The ability of the secretagogues to regulate protein expression of CYP21 and CYP17 was examined. H-295 cells were incubated in the presence or absence of forskolin, A-II and insulin. Increases in protein expression of CYP21 were seen in the presence of forskolin, A-II and forskolin in combination with A-II (Fig. 4A). Protein expression of CYP17 was increased in the presence of forskolin and insulin alone, and in combination (Fig. 4B).

\section{Regulation of SF-1 and nur77 in the adrenal cortex}

To examine whether forskolin, A-II and insulin mediate their effects through SF-1 and nur77, protein expression of these transcription factors in adrenocortical cells was assessed. SF-1 was found to be expressed predominantly within the nucleus of H-295 cells. Following treatment with forskolin an increase in nuclear expression of SF-1 was observed (Fig. 5A). Forskolin, A-II and insulin all induced an increase in the protein expression of SF-1 (Fig. 5B).

Nur77 was localised within the human adrenal cortex and the protein expression following stimulation examined. Nur77 was expressed predominantly within the nuclei of cells of the zona fasciculata and zona glomerulosa (Fig. 6A). Immunocytochemical studies of nur77 expression in H-295 cells demonstrated an increase in the nuclear expression of nur77 following $2 \mathrm{~h}$ incubation with forskolin (Fig. 6B). Protein expression of nur77 in H-295 cells was found to be low as determined by Western blotting, with an increase in expression observed when cells were incubated with all secretagogues tested, in particular forskolin in combination with A-II (Fig. 6C).

\section{Activation of SF-1 and nur77}

A consensus-binding site for the nuclear receptor SF-1 has been located within the proximal promoter region of the steroid hydroxylase enzymes (Parker \& Schimmer 1997). Because of the role of ACTH, A-II and insulin in inducing the expression of these genes and the ability of these secretagogues to increase the protein expression of SF-1, a role for ACTH, A-II and insulin in signalling through SF-1 was sought. Using published oligonucleotide sequences (Wilson et al. 1991, Hanley et al. 2001), the ability of nuclear extracts from non-stimulated H-295 cells to bind to the DNA-binding motif compared with cells stimulated for $2 \mathrm{~h}$ with forskolin, A-II and insulin was examined. Binding was specific as demonstrated by successful competition with excess homologous oligonucleotide. A super shift induced by pre-incubation of the nuclear extracts with anti-SF-1 established that SF-1 was present in the protein-DNA complex. The protein-DNA complex was differentially inducible with forskolin, and to a lesser extent insulin and A-II (Fig. 7A).

The classic consensus-binding site for nur77 (NBRE) has previously been described on the promoter region of CYP21 (Wilson et al. 1993, Chang \& Chung 1995). Since forskolin and A-II can induce the protein expression of CYP21 the ability of these secretagogues to signal through nur77 was examined. Specific binding was demonstrated as above. Pre-incubation of the nuclear extracts with an antibody directed against nur77 induced a shift in the 
A

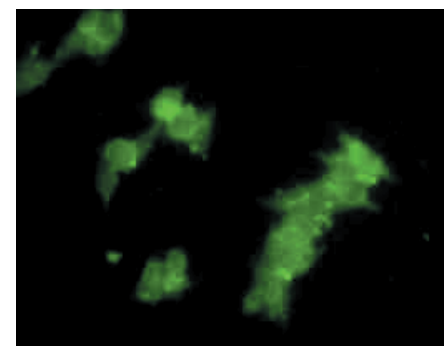

Control

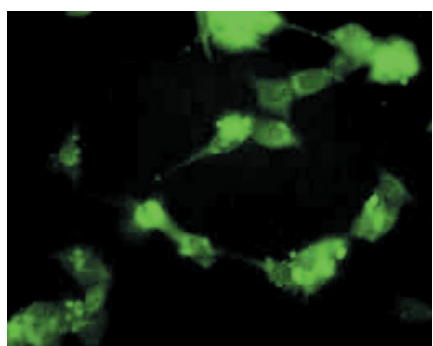

Forskolin

\section{B}
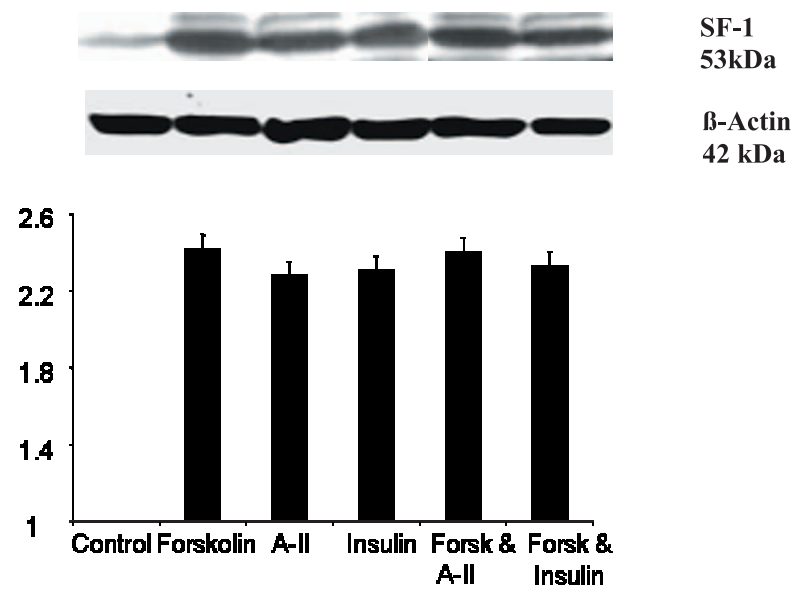

Figure 5 (A) Immunofluorescence stain for SF-1 in H-295 adrenocortical cells. Original magnification $\times 200$ (B) Representative protein immunoblot of SF-1 protein expression in $\mathrm{H}-295$, following $6 \mathrm{~h}$ stimulation with forskolin $10^{-7} \mathrm{M}, \mathrm{A}-\mathrm{II} 10^{-7} \mathrm{M}$ and insulin

$10^{-7} \mathrm{M}$. Results are representative of those obtained in three separate experiments.

$\beta$-actin represents equal loading of samples.

protein-DNA complex, verifying that nur77 was present in the complex. Increased binding was observed in the protein-DNA complex with all secretagogues, in particular forskolin in combination with A-II (Fig. 7B).

\section{Discussion}

Differential production of adrenal steroids has been thought to be achieved at least in part through cell specific production of individual steroids (Parker \& Schimmer 1994, Zhang \& Mellon 1997). However, we have recently reported that all adrenocortical cells are capable of producing a range of steroids, though the relative production of cortisol, androgens and aldosterone differs (Young et al. 2003). The relative production of adrenal steroids is achieved through the differential expression of key steroidogenic enzymes, under the influence of secretagogues ( $\mathrm{Hu}$ et al. 2001). ACTH is the classic secretagogue for both cortisol and adrenal androgens, whereas A-II, though primarily concerned with the production of aldosterone, has also been shown to upregulate cortisol production (Bird et al. 1993a, Rainey et al. 1993). Both clinical and in vitro studies have implicated insulin in the regulation of adrenal androgen production (Kristiansen et al. 1997, Qin \& Rosenfield 1998). In this study, we found that H-295 cells produced significantly more cortisol relative to androstendione in the presence of forskolin and forskolin in combination with A-II. These patterns of steroid production were reflected in human adrenocortical cell suspensions though differences did not reach statistical significance.

The relative production of cortisol and adrenal androgens is a function of the differential expression of

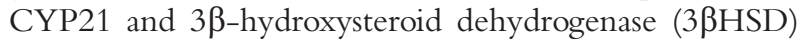
to CYP17. Where ACTH upregulates all steroid enzymes, A-II signalling via the PKC pathway positively regulates both CYP21 and 3 $3 \mathrm{HSD}$, and negatively regulates CYP17 (Bird et al. 1998). In this study, secretion of cortisol and the adrenal androgen androstenedione was examined, and as $3 \beta \mathrm{HSD}$ is involved in the production of androstenedione and cortisol, the relative expression of CYP21 to CYP17 was examined. The spatial localisation of these enzymes was determined in the adult human 
$\mathbf{A}$

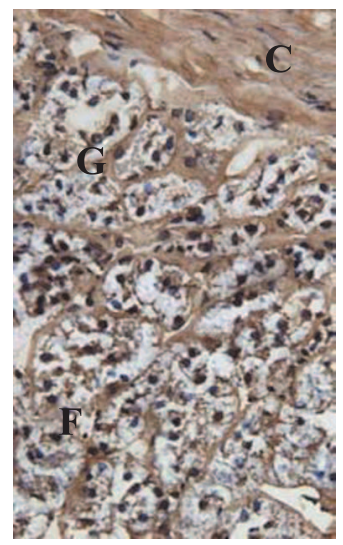

B

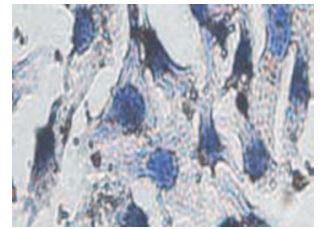

Control
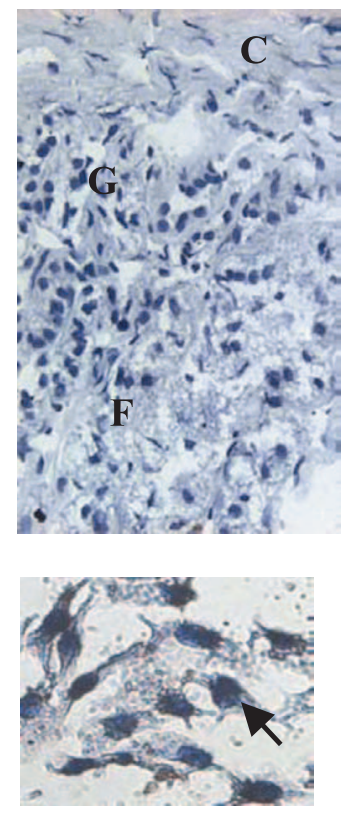

Forskolin
C
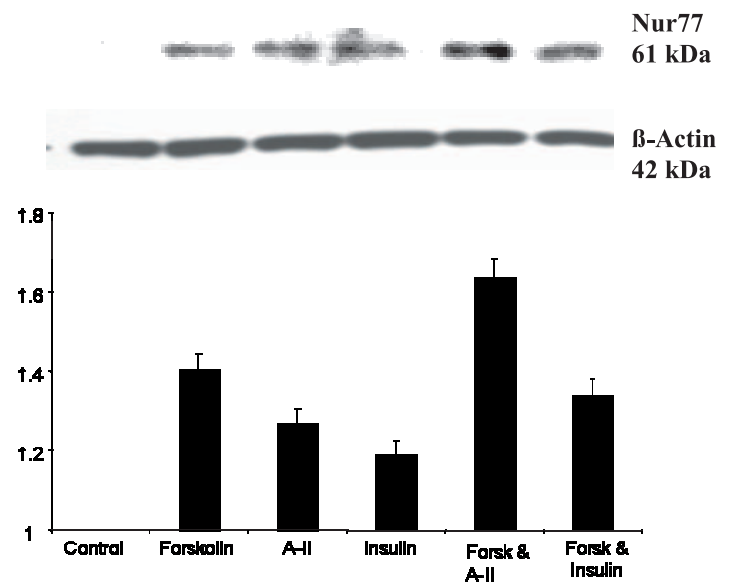

Figure 6 (A) Photomicrograph of immunohistochemical stain for nur77 in human adrenal cryosections counterstained with haematoxylin (left) and matched negative controls (right). Brown indicates positive stain, F, fasciculata; G, glomerulosa; C, capsule. (Original magnification $\times 400$ ). (B) Immunocytochemical stain for nur77 in unstimulated $\mathrm{H}-295$ cells (left) and following $2 \mathrm{~h}$ stimulation with forskolin $10^{-7} \mathrm{M}$ (right). (C) Representative protein immunoblot of nur77 total protein expression in $\mathrm{H}-295$ cells. Results are representative of those obtained in three separate experiments. $\beta$-actin represents equal loading of samples.

adrenal cortex. CYP21 and CYP17 were both localised to the cytoplasm of zona fasciculata and zona reticularis cells. Low expression of CYP21 was also detected within the zona glomerulosa whereas CYP17 was found to be expressed exclusively in the cytoplasm of cells in the zona fasciculata and reticularis. These classic patterns of steroid enzyme expression are consistent with those described by others (Bird et al. 1996, Morley et al. 1996).

In this study ACTH, A-II and insulin were found to differentially regulate cortisol and adrenal androgen production. Increases in CYP21 at the mRNA level have been described in the presence of both ACTH and A-II (Bird et al. 1998), though little has been shown regarding alterations in protein expression. Here we found increased CYP21 mRNA and protein with forskolin and A-II individually and forskolin in combination with A-II. The role of insulin in the regulation of CYP21 expression remains controversial (Klein et al. 1992, Endoh et al. 1998). We observed no alteration in the expression of CYP21 at either the mRNA or protein level in the presence of insulin, moreover insulin appeared to abrogate increases in CYP21 protein seen in the presence of forskolin. Conversely, forskolin and insulin have been implicated in the upregulation of CYP17 (Bird et al. 1993b, Qin \& Rosenfield 1998), whereas the role of A-II remains to be fully elucidated (Lebrethon et al. 1994, Parker \& Schimmer 1994, Viard et al. 1994). In this study CYP17 mRNA and protein expression were found to be upregulated in the presence of forskolin and insulin. These data implicate ACTH, A-II and insulin in the differential regulation of cortisol and adrenal androgens through their relative modulation of CYP21 and CYP17 expression.

SF-1 is an important regulator of the expression of cytochrome P450 steroid hydroxylase enzymes in humans. This shared regulatory protein can interact with a number of variations of an AGGTCA motif on the promoter region of the steroid enzymes (Rice et al. 1991, Morohashi et al. 1992). Using in situ hybridisation the expression of SF-1 has been demonstrated throughout the adrenal cortex (Ikeda et al. 1993), correlating with its proposed role in regulating steroid hydroxylases. Hormonal regulation of SF-1 remains controversial; it has been suggested that SF-1 transcripts are not altered in response to treatment with secretagogues (Parker \& Schimmer 1997), whereas others have shown increases in SF-1 mRNA in the presence of both forskolin and A-II (Enyeart et al. 1996). In this study protein expression of SF-1 was found to be expressed at a basal level and was elevated in the presence of all secretagogues tested.

C-terminal regions of mammalian SF-1 are highly conserved within their putative ligand-binding domains, which is consistent with the theory that SF-1 is activated by a ligand. A specific SF-1 ligand remains elusive, although hydroxycholesterol has been suggested (Janowski et al. 1996). Alternatively regulation of SF-1 activity may be indirect through specific upstream events or may be activated through post-translational modifications. A conserved phosphorylation motif for cAMP-dependent protein kinase provides a candidate at which a ligandindependent modulation of activity may be affected. 


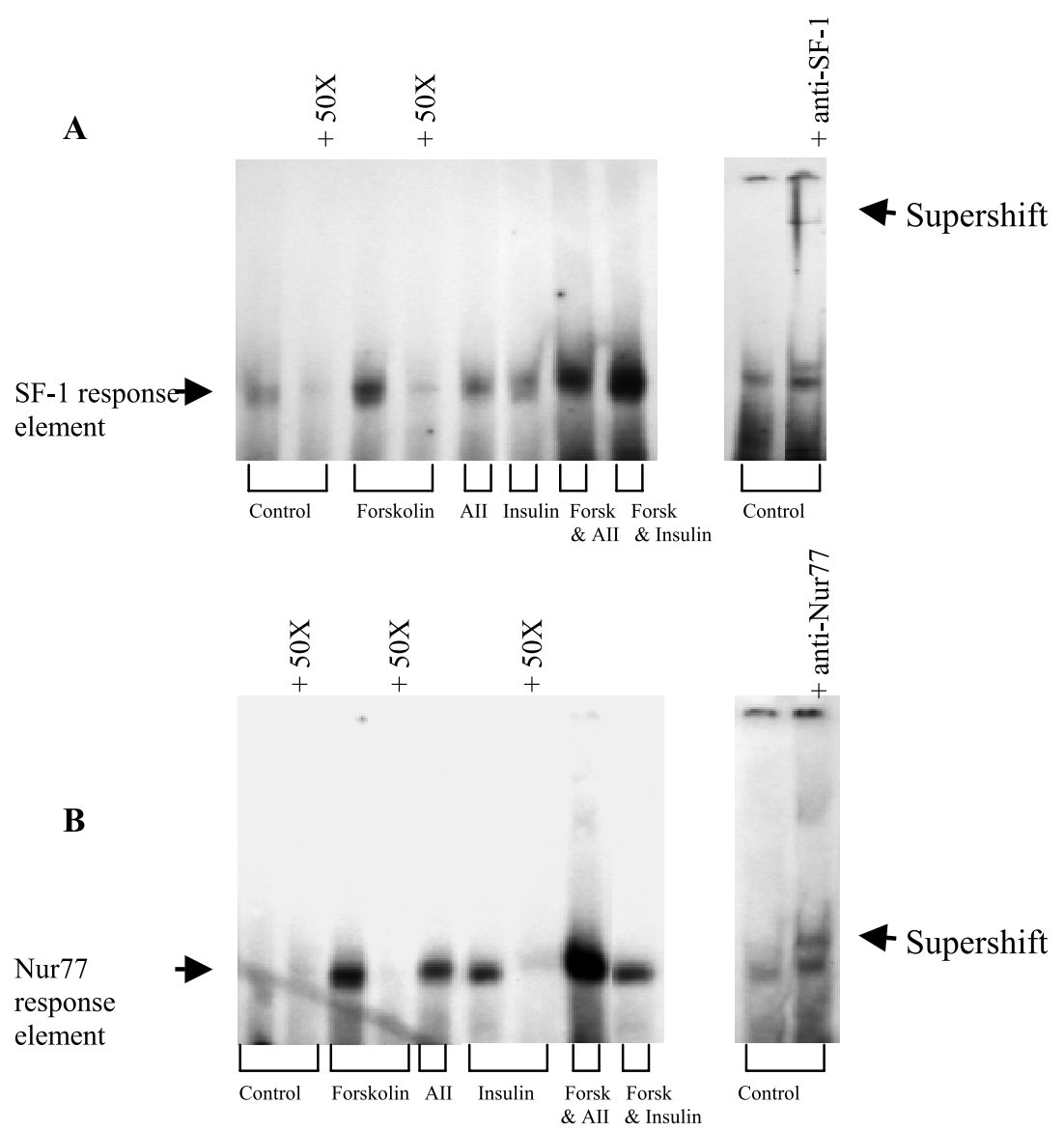

Figure 7 Electrophoretic mobility shift analysis of nuclear extracts from $\mathrm{H}-295$ cells. Nuclear protein extracts from $\mathrm{H}-295$ cells in the presence and absence of forskolin $10^{-7} \mathrm{M}$, A-II $10^{-7} \mathrm{M}$ and insulin $10^{-7} \mathrm{M}$ were compared for increased binding to (A) $\alpha^{32}$ P-dCTP-labelled SF-1 response element and (B) $\alpha^{32}$ P-dCTP-labelled nur77 response element (NBRE). DNA protein interactions were assayed in the presence of $\times 50$ molar excess of homologous oligonucleotide (every second lane). Nuclear protein extracts were pre-incubated in the presence of anti-SF-1 or anti-nur77. Results are representative of those obtained in three separate experiments.

In these studies the adenylate cyclase activator forskolin, and to a lesser extent insulin and A-II, induced SF-1 binding to its response element in $\mathrm{H}-295$ adrenocortical cells.

Other transcription factors, which are expressed in the adrenal cortex, include the nurr family of orphan nuclear recptors. The role of the family in adrenal cortical steroidogenesis is gathering interest. Recent studies have demonstrated a role for nurr1 and nur77 in the transcriptional regulation of CYP11B2 (encoding aldosterone synthase) implicating nurr in the regulation of aldosterone production (Bassett et al. 2004). Binding regions for the orphan nuclear receptor nur77 have been identified on the promoter region of CYP21 (Wilson et al. 1993, Chang \& Chung 1995). Regulation of this nuclear receptor has been observed in the presence of ACTH and A-II in both murine and bovine adrenocortical cells (Enyeart et al.
1996, Li \& Lau 1997). In this study nur77 was found to be expressed predominantly within the nuclei of cells of the human zona glomerulosa and fasciculata. In contrast to the response of SF-1 observed in the presence of secretagogoues, a particular increase in nur77 protein expression was detected in response to forskolin in combination with A-II. Similarly, the greatest binding of nur77 to its response element was observed in the presence of forskolin in combination with A-II, thus implicating these secretagogues in the regulation of nur 77 . Therefore, differences between SF-1 and nur77 in spatial localisation within the adrenal cortex, expression and DNA interaction in response to secretagogues suggest that these transcription factors may differentially modulate the transcription of genes in the human adrenal cortex.

These data provide evidence that secretagogues can signal through nur77 to regulate the production of 
key steroidogenic enzymes. We propose that SF-1 is responsible for regulating all hydroxylase enzymes under basal conditions and in the presence of secretagogues. Stimulation through the adenylate cyclase and the PKC pathways however also leads to the induction of nur77, resulting in a further activation of CYP21. Therefore in the human adrenal, ACTH and A-II may preferentially stimulate cortical production by signalling through nur77.

\section{Acknowledgements}

We are very grateful to Prof. J I Mason, Department of Clinical Biochemistry, Royal Infirmary of Edinburgh NHS trust, Lauriston Place, Edinburgh, UK, for his generous gift of CYP21 and CYP17 antibodies. We are also grateful to Prof. W E Rainey, Department of Obstetrics and Gynecology, Reproductive Endocrinology, UT Southwestern Medical Center, Dallas, TX, USA for his generous gift of CYP21 and CYP17 cDNA.

\section{Funding}

This work was supported by the Health and Research Board of Ireland and Enterprise Ireland.

\section{References}

Barnes R \& Rosenfield RL 1989 The polycystic ovary syndrome: pathogenesis and treatment. Annals of Internal Medicine $\mathbf{1 1 0}$ 386-399.

Bassett MH, Suzuki T, Sasano H, White PC \& Rainey WE 2004 The NGFIB family of nuclear receptors regulates adrenal aldosterone production. Molecular Endocrinology 18 279-290.

Bird IM, Hanley NA, Word RA, Mathis JM, McCarthy JL, Mason JI \& Rainey WE 1993a Human NCI-H295 adrenocortical carcinoma cells: a model for angiotensin-II-responsive aldosterone secretion. Endocrinology 133 1555-1561.

Bird IM, Mason JI, Oka K \& Rainey WE 1993b Angiotensin-II stimulates an increase in cAMP and expression of 17 alpha-hydroxylase cytochrome P450 in fetal bovine adrenocortical cells. Endocrinology 132 932-934.

Bird IM, Zheng J, Corbin CJ, Magness RR \& Conley AJ 1996 Immunohistochemical analysis of AT1 receptor versus P450c17 and 3 beta HSD expression in ovine adrenals. Endocrine Research 22 349-353.

Bird IM, Mason JI \& Rainey WE 1998 Protein kinase A, protein kinase $\mathrm{C}$, and $\mathrm{Ca}\left({ }^{2+}\right)$-regulated expression of 21-hydroxylase cytochrome P450 in H295R human adrenocortical cells. Journal of Clinical Endocrinology and Metabolism 83 1592-1597.

Chang SF \& Chung BC 1995 Difference in transcriptional activity of two homologous CYP21A genes. Molecular Endocrinology 9 1330-1336.

Clarke D, Fearon U, Cunningham SK \& McKenna TJ 1996 The steroidogenic effects of beta-endorphin and joining peptide: a potential role in the modulation of adrenal androgen production. Journal of Endocrinology 151 301-307.

Endoh A, Yang L \& Hornsby PJ 1998 CYP21 pseudogene transcripts are much less abundant than those from the active gene in normal human adrenocortical cells under various conditions in culture. Molecular and Cellular Endocrinology 137 13-19.
Enyeart JJ, Boyd RT \& Enyeart JA 1996 ACTH and AII differentially stimulate steroid hormone orphan receptor mRNAs in adrenal cortical cells. Molecular and Cellular Endocrinology 124 97-110.

Fearon U, Clarke D, McKenna TJ \& Cunningham SK 1998 Intra-adrenal factors are not involved in the differential control of cortisol and adrenal androgens in human adrenals. European Journal of Endocrinology 138 567-573.

Gell JS, Carr BR, Sasano H, Atkins B, Margraf L, Mason JI \& Rainey WE 1998 Adrenarche results from development of a 3 beta-hydroxysteroid dehydrogenase-deficient adrenal reticularis. Journal of Clinical Endocrinology and Metabolism 83 3695-3701.

Hanley NA, Rainey WE, Wilson DI, Ball SG \& Parker KL 2001 Expression profiles of SF-1, DAX1, and CYP17 in the human fetal adrenal gland: potential interactions in gene regulation. Molecular Endocrinology 15 57-68.

Hu MC, Chiang EF, Tong SK, Lai W, Hsu NC, Wang LC \& Chung BC 2001 Regulation of steroidogenesis in transgenic mice and zebrafish. Molecular and Cellular Endocrinology 171 9-14.

Ikeda Y, Lala DS, Luo X, Kim E, Moisan MP \& Parker KL 1993 Characterization of the mouse FTZ-F1 gene, which encodes a key regulator of steroid hydroxylase gene expression. Molecular Endocrinology 7 852-860.

Janowski BA, Willy PJ, Devi TR, Falck JR \& Mangelsdorf DJ 1996 An oxysterol signalling pathway mediated by the nuclear receptor LXR alpha. Nature 383 728-731.

Klein NA, Andersen RN, Casson PR, Buster JE \& Kramer RE 1992 Mechanisms of insulin inhibition of ACTH-stimulated steroid secretion by cultured bovine adrenocortical cells. Journal of Steroid Biochemistry and Molecular Biology 41 11-20.

Kristiansen SB, Endoh AP, Casson R, Buster JE \& Hornsby PJ 1997 Induction of steroidogenic enzyme genes by insulin and IGF-I in cultured adult human adrenocortical cells. Steroids 62 258-265.

Lala DS, Rice DA \& Parker KL 1992 Steroidogenic factor I, a key regulator of steroidogenic enzyme expression, is the mouse homolog of fushi tarazu-factor I. Molecular Endocrinology 6 1249-1258.

Lebrethon MC, Jaillard C, Defayes G, Begeot M \& Saez JM 1994 Human cultured adrenal fasciculata-reticularis cells are targets for angiotensin-II: effects on cytochrome P450 cholesterol side-chain cleavage, cytochrome P450 17 alpha-hydroxylase, and 3 betahydroxysteroid-dehydrogenase messenger ribonucleic acid and proteins and on steroidogenic responsiveness to corticotropin and angiotensin-II. Journal of Clinical Endocrinology and Metabolism $\mathbf{7 8}$ 1212-1219.

Li Y \& Lau LF 1997 Adrenocorticotropic hormone regulates the activities of the orphan nuclear receptor Nur77 through modulation of phosphorylation. Endocrinology 138 4138-4146.

McKenna TJ \& Cunningham SK 1995 Adrenal androgen production in polycystic ovary syndrome. European Journal of Endocrinology 133 383-389.

Morley SD, Viard I, Chung BC, Ikeda Y, Parker KL \& Mullins JJ 1996 Variegated expression of a mouse steroid 21-hydroxylase/beta-galactosidase transgene suggests centripetal migration of adrenocortical cells. Molecular Endocrinology 10 585-598.

Morohashi K, Honda S, Inomata Y, Handa H \& Omura T 1992 A common trans-acting factor, Ad4-binding protein, to the promoters of steroidogenic P-450s. Journal of Biological Chemistry 267 17913-17919.

Parker KL \& Schimmer BP 1994 The role of nuclear receptors in steroid hormone production. Seminars in Cancer Biology 5 317-325.

Parker KL \& Schimmer BP 1997 Steroidogenic factor 1: a key determinant of endocrine development and function. Endocrine Reviews 18 361-377.

Peter M \& Dubuis JM 2000 Transcription factors as regulators of steroidogenic P-450 enzymes. European Journal of Clinical Investigation 30 14-20. 
Qin KN \& Rosenfield RL 1998 Role of cytochrome P450c17 in polycystic ovary syndrome. Molecular and Cellular Endocrinology 145 111-121.

Rainey WE, Bird IM, Sawetawan C, Hanley NA, McCarthy JL, McGee EA, Wester R \& Mason JI 1993 Regulation of human adrenal carcinoma cell (NCI-H295) production of C19 steroids. Journal of Clinical Endocrinology and Metabolism 77 731-737.

Rice DA, Mouw AR, Bogerd AM \& Parker KL 1991 A shared promoter element regulates the expression of three steroidogenic enzymes. Molecular Endocrinology 5 1552-1561.

Viard I, Penhoat A, Ouali R, Langlois D, Begeot M \& Saez JM 1994 Peptide hormone and growth factor regulation of nuclear proto-oncogenes and specific functions in adrenal cells. Journal of Steroid Biochemistry and Molecular Biology 50 219-224.

Wilson TE, Fahrner TJ, Johnston M \& Milbrandt J 1991 Identification of the DNA binding site for NGFI-B by genetic selection in yeast. Science 252 1296-1300.
Wilson TE, Mouw AR, Weaver CA, Milbrandt J \& Parker KL 1993 The orphan nuclear receptor NGFI-B regulates expression of the gene encoding steroid 21-hydroxylase. Molecular and Cellular Biology 13 861-868.

Young, LS, Murphy G, Kelly SN, Smith TP, Cunningham SK \& McKenna TJ 2003 Differential production of adrenal steroids by purified cells of the human adrenal cortex is relative rather than absolute. European Journal of Endocrinology 148 139-145.

Zhang P \& Mellon SH 1997 Multiple orphan nuclear receptors converge to regulate rat $\mathrm{P} 450 \mathrm{c} 17$ gene transcription: novel mechanisms for orphan nuclear receptor action. Molecular Endocrinology 11 891-904.

Received in final form 9 December 2003

Accepted 14 January 2004 